Georgia State University College of Law Reading Room

CNCR-Hewlett Foundation Seed Grant White

Papers

Centers

2005

\title{
Interactive Reflection as a Creative Teaching Strategy
}

Allison Patten McGuire

Lin Inlow

Georgia State University

Follow this and additional works at: https://readingroom.law.gsu.edu/seedgrant

Part of the Law Commons

Institutional Repository Citation

Patten McGuire, Allison and Inlow, Lin, "Interactive Reflection as a Creative Teaching Strategy" (2005). CNCR-Hewlett Foundation Seed Grant White Papers. 17.

https://readingroom.law.gsu.edu/seedgrant/17

This Article is brought to you for free and open access by the Centers at Reading Room. It has been accepted for inclusion in CNCR-Hewlett Foundation Seed Grant White Papers by an authorized administrator of Reading Room. For more information, please contact mbutler@gsu.edu. 


\section{Interactive Reflection as a Creative Teaching Strategy}

ALLISON PATTEN MCGUIRE, LIN INLOW

The purpose of this article is to present interactive reflection as a creative teaching strategy and demonstrate its role in teaching conflict resolution. The article discusses examples of interactive reflection in action and identifies potential barriers or roadblocks to using such a strategy.

Tteractive reflection (IR) is a structured social feedback process through which learners in small groups help one another identify their strengths and weaknesses in interpersonal skills, specifically those related to conflict resolution. IR can serve as the foundation for learning activities such as role play and evaluation in which increased awareness of and improvement in conflict resolution skills is the objective. IR serves both an interpersonal purpose, by building a learning community, and an intrapersonal purpose, by helping participants become skilled mediators.

The Consortium on Negotiation and Conflict Resolution (CNCR) coined the term interactive reflection to describe some of their particular strategies of teaching conflict resolution skills. As the provider of technical assistance to the University System of Georgia's Initiative and Policy Direction on Conflict Resolution (see the Appendix), CNCR teaches conflict resolution skills, specifically mediation, negotiation, and communication. Innovations in pedagogy facilitate building capacity for managing conflict at the thirty-four institutions and training mediators for Georgia's systemwide mediation program. 


\section{What Does Interactive Reflection Look Like in a Real-Life Training Exercise?}

As part of the first day's orientation to the training environment and to the philosophy of instruction, CNCR faculty spend some time discussing giving and receiving feedback as a means to improving interpersonal awareness and effectiveness. The Johari Window (Luft, 1970) is a model that explains the awareness of human behavior, feelings, and motivation. The model (Figure 1) outlines behavior in terms of its awareness to oneself and other people.

Quadrant one, the open area, represents behavior and motivations that are known to the learner and to others in the group. Other quadrants represent areas of less awareness: the learner is blind to the contents of quadrant two, while his or her peers may notice them. The learner is aware of but hides the contents of quadrant three from others, while quadrant four represents behavior, feelings, and ideas that are unknown by the learner and the other members of the group.

Figure 1. Johari Window

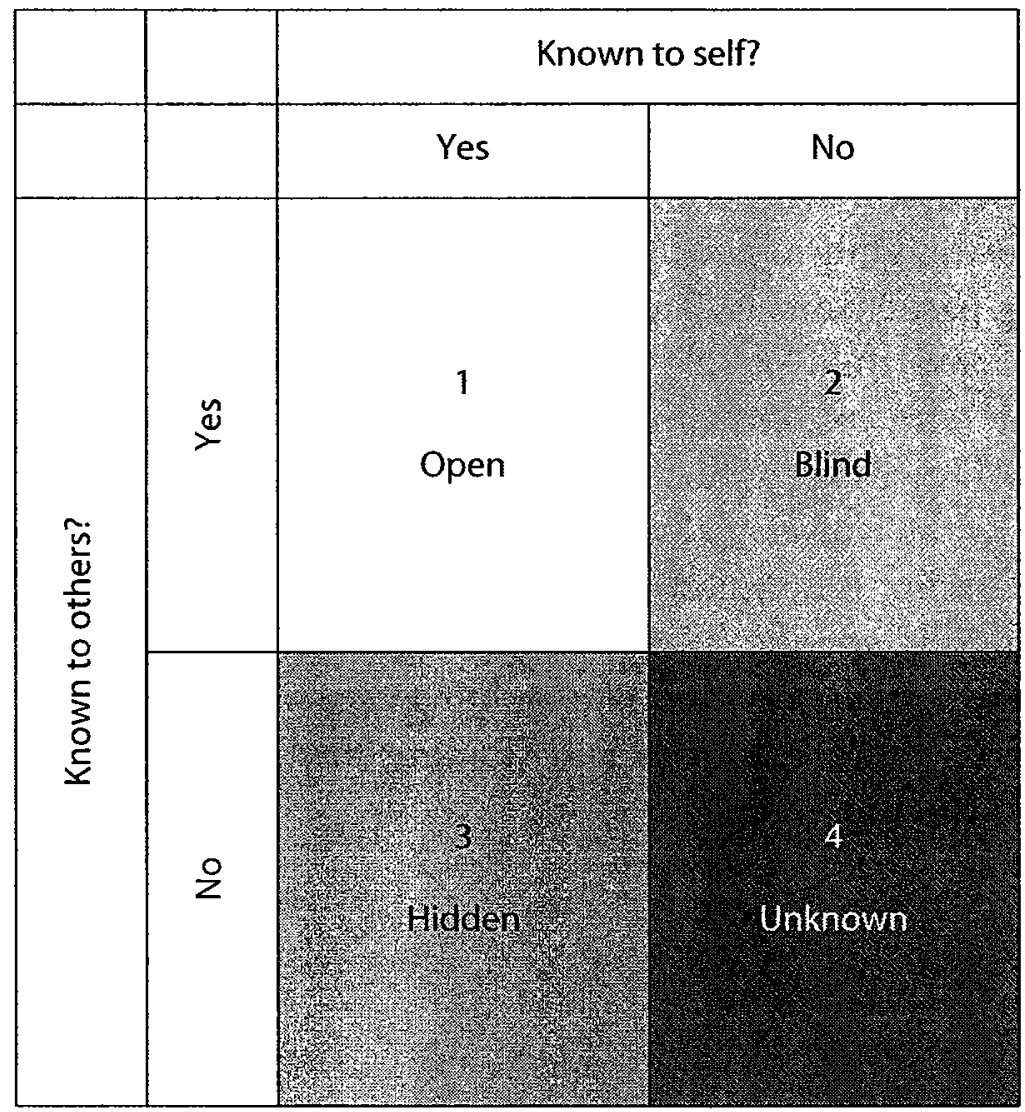


Using this model, we express to the participants that our goal is to give them opportunities to enlarge quadrant one-to become more aware of their behavior, feelings, and motivation as they work in conflict situations and more specifically as they become a third-party intervenor. The principles of the Johari Window that are integral to this training include the notion that as trust develops among learners, the open area increases, while the hidden and blind areas decrease (Luft, 1970). The larger the open areas become, the more effectively learners can communicate with one another.

Since the thirty-two-hour training is interactive and experiential, we encourage participants to take risks as they learn about mediation and about themselves. Facilitators are also sensitive to the fact that it can be difficult for learners to give up beliefs held in quadrant two, and that a threatening environment causes learners to move into defensive modes of thinking and lose their awareness of self and others. For this reason and out of respect for learners, participants are given permission to pass on any of the exercises that they believe would not be beneficial for them.

The CNCR Summer Institute mediation training implemented interactive reflection using two teaching strategies: a survey exercise and a debriefing model for mediation role plays. In the survey exercise, participants were given a list of personality traits or behaviors related to how they handle conflict and were asked to rate themselves on a scale of 1 to 5 in terms of how strong they perceived themselves to be along these dimensions. (As examples, two items on the survey were "My body language shows that I am a good listener" and "In conflict I try to dominate the other person.") The survey is administered as participants enter and settle into their role as student and before any instruction begins. It is then collected and not referred to again until the evening before the last class. Four days after this self-rating, participants were asked to rerate themselves (without referring to their initial rating), taking into account what they had learned about themselves, others, and conflict throughout the previous days of training.

Participants also met in triads in which two people rated the third person on these same dimensions and discussed him or her until they reached consensus. The third person had the opportunity to hear colleagues' impressions of his or her behavior, affording valuable insight into the impact one's behavior has on others.

Once the feedback session is completed, the exercise is debriefed in a plenary session. Debriefing questions are designed to facilitate appreciation for the students' willingness to take risks by sharing their strengths and weaknesses and to encourage introspection and reflection beyond training 
to practice. Examples of questions are "During this training what awareness about yourself and/or the mediation process do you believe will be most beneficial to you?" "How will you use this feedback to improve your mediation skills?" "How does being a participant in the last part of this exercise inform you about the experience of being a party in a mediation?" Students leave the Summer Institute with the survey as a reminder of their experience of giving and receiving feedback.

The second tool the CNCR used to promote interactive reflection was the coaches' debriefing model for mediation simulations. As an integral part of mediation training, each person was required to participate in mediation role plays that occurred in the last two days of the training. Experienced mediators who had participated in four hours of training in "coaching mediation role plays" observed these mediations and facilitated a debriefing at the end of each one using the CNCR model of coaching, during which time the parties, the mediator, and the coach used interactive reflection to evaluate the mediation process.

Coaches are taught to give very little feedback, if any, during the roleplay debriefing. Their primary role is to facilitate the feedback session rather than provide feedback. In any simulation, there are four roles to play: the mediator, a mediator shadow (a participant who does not have a role other than observation of the mediator), and two parties. Coaches facilitate the feedback session by first asking the mediator "What worked?" "What did not work?" and "What would you do differently the next time?" During the responses, there is discussion and feedback given to the mediator by the other role players. Then the coach asks each of the parties "As the party, what did the mediator do that worked?" and "As the party, what would you have liked the mediator to do differently?" Finally, the mediator shadow is asked "What lessons have you learned from your role as a shadow in this mediation?"

If the coach has an observation to share that has not previously been discussed, then the coach closes the debriefing with observations. Most often, if the coach has been facilitative there is little for him or her to say; usually the students bring up all the salient points of the role play. If students are providing feedback in a fashion that is not useful, the coach uses a variety of facilitation skills such as reframing and inquiry to elicit more helpful feedback. At these times, the coach is more active while always protecting the psychological safety of the debriefing. Participants learn not only about the process of mediation and their developing skills but also about giving and receiving feedback. 


\section{What Is the Value of Using Interactive Reflection for Teaching Conflict Resolution?}

As an interpersonal activity, interactive reflection builds a learning community among participants through promoting open and honest communication. The importance of such a learning community is underscored by Raider and colleagues (Raider, Coleman, and Gerson, 2000), who emphasize that for learning to occur it is critical that "all feel safe enough to try on new skills and attitudes" (p. 500). IR fosters this safe environment by creating trust among learners, promoting collegiality, and encouraging effective communication. A safe environment is particularly important for participants who are learning about conflict, which can involve strong emotions and deeply held assumptions and beliefs (Stone, Patton, and Heen, 1999).

Building community during training demands that learners reframe their own roles in the learning transaction, first by transforming the concept of the learner from the traditional notion of the person who is there simply to passively receive information from the teachers. In contrast, in the learning community the student is multidimensional, not merely an academic drone, but a human with physical, emotional, and spiritual dimensions to bring to the task of learning as well as cognitive ones (Bransford, Brown, and Cocking, 2000; Palmer, 1998).

Within such a learning community, interactive reflection promotes respect for diversity by creating the opportunity for participants from varying levels of power to participate as equals on a level playing field. Because conflict is context-based, each participant arrives at the training with a particular conflict management style that has developed at least in part according to the power position he or she holds in organizations and communities. Instead of replicating this unequal distribution of power, IR gives each participant the opportunity to have a voice in the learning process. Learning to resolve conflict is a transformational learning experience; theories of such learning "presume ... relations of equality among participants in reflective discourse when, in actuality, most human relationships are asymmetrical" (Belenky and Stanton, 2000, p. 73).

Through IR, participants may come to see their assumptions and biases; such reflection fosters open and honest communication about these perspectives and offers the chance to see the role that power plays in conflict situations (Schön, 1983). This reflection promotes multicultural competence because it can "increase students' recognition of cultural contexts 
outside their own experience ... [and] shake some students loose from simplistic thinking and ethnocentric biases" (Kurfiss, 1988, p. 68). CNCR participants from marginalized groups have reported that the training indeed creates a safe environment that does not reflect the power inequities experienced in daily life.

Finally, within a learning community that respects the diversity of participants, IR helps manage the defensiveness that inevitably arises during the learning process. London and colleagues (London, Larsen, and Thisted, 1999) point out that those with the greatest need for feedback are often the most resistant to it. People who need to be redirected in their behavior fail to do so either because of their own defensiveness or because others do not give constructive or helpful feedback; this lack of learning creates negative outcomes. IR offers instruction and support around constructive feedback and the opportunity to practice giving and receiving it. London and colleagues also report that receiving constructive feedback makes people feel empowered.

Besides facilitating the social relationships that are critical to creating a good learning environment, interactive reflection serves as an intrapersonal tool for increasing the effectiveness of conflict management training in three important ways. First, IR may improve participants' perspectivetaking abilities. Kurfiss (1988) reports that structured critical reflection promotes perspective taking, an invaluable skill for conflict resolvers.

Second, interactive reflection embraces the opportunity to practice giving and receiving feedback. Page and Hulse-Killacky (1999) highlight the benefits of students' practicing giving and receiving "corrective feedback" in a group training environment; among these outcomes are overcoming the common fear of giving negative feedback, confronting beliefs about oneself, learning to give feedback in ways that help people learn, and seeing the impact one's own behavior has on others.

According to Mezirow, "Transformative learning refers to the process by which we transform our taken-for-granted frames of reference (meaning perspectives, habits of mind, mind-sets) to make them more inclusive, discriminating, open, emotionally capable of change, and reflective so that they may generate beliefs and opinions that will prove more true or justified to guide action" (2000, pp. 7-8). Transformative learning is more personal than instrumental learning, because it requires that students not only absorb information and skills but also integrate new knowledge into their own ways of thinking and being in the world, in social contexts as well. 
Whereas traditional education has focused on instrumental learning in an isolated, individualistic environment, transformative learning requires a social context to create the discourse and dissonance required for real learning to occur (Mezirow, 2000). Since adoption of the University System of Georgia's Initiative and Policy Direction on Conflict Resolution in 1995, CNCR has trained more than three hundred mediators, many of whom have little opportunity to mediate cases either on their campus or for the university system. In spite of this, participants view the training as developing life skills and thus a meaningful, transformative experience.

Experts in the principles of adult education (notably Mezirow, King and Kitchener, Argyris, and Marsick and Sauquet) posit reflection as the key to transformative learning. This is both the good news and the bad news. The good news is that both research and practice have yielded a solid understanding of how to foster reflection in adult learners. Dialogues, ill-structured problems, social situations, and cooperative experiments designed to provoke disequilibrium among learners set the stage for productive reflection. A facilitator-or even a few guided questions around which a person may journal-can leverage the learning power from this disequilibrium by guiding learners through a cycle of reflection, meaning making, and theory building which can then inform future action (Kolb, 1984). The good news is that if learners can be led to reflect, they can be supported in truly transformative learning.

An important part of benefiting from feedback is knowing what kind of feedback to solicit in the first place-that is, knowing what one does not know. This metacognition (thinking about and evaluating one's own thoughts) is a complex cognitive skill that emerges as a characteristic of postformal development. In his 1994 book In Over Our Heads: The Mental Demands of Modern Life, Robert Kegan argues that postformal thinking skills such as metacognition and critical reflection are not commonly available to adults. Research suggests that experience with higher education facilitates development of these skills in adult learners, whereas general life experience, however valuable, does not typically contribute to these specific cognitive abilities.

Interactive reflection may facilitate self-discovery, or insight, among program participants. Al-Tabtaibai, Alex, and Aboualfotouh (2001) write that although people are often confident that they understand their own biases, most actually have a very limited understanding of their own judgment processes. IR structures the kind of feedback and reflection that gives 
the participant information about his or her own cognitions and attitudes related to conflict.

\section{What Possible Roadblocks Can Make Interactive Reflection Difficult to Teach?}

Participants are often unwilling or uneasy about participating in two essential pieces of the interactive reflection process: giving and receiving critical feedback. People's unwillingness to present critical feedback has been widely documented; Page and Hulse-Killacky (1999) report that even in situations designed for group and individual learning people are quite fearful and hesitant about giving critical feedback.

Because of this tendency, coaches need to be sensitive not to the defensiveness of the participants with whom they work but also to their own propensity to resist feedback. In fact, CNCR training experiences show that, as Argyris (1991) suggests, even the coaches themselves are sometimes resistant to critical feedback. To manage this challenge, the CNCR program organizers have included sessions for debriefing with their staff and coaches. These daily sessions take place immediately after classes have ended; they give the leaders a chance to reflect on and share their personal reactions to the learners and teaching experience, as well as to review the feedback from learners that is shared after each teaching module.

Just as participants prefer not to give others critical feedback, they would also like to receive the same deference. When critical feedback is presented, participants often become quite defensive and angry: "Transformative learning, especially when it involves subjective reframing, is often an intensely threatening emotional experience in which we have to become aware of both the assumptions undergirding our ideas and those supporting our emotional responses to the need to change" (Mezirow, 2000, pp. 6-7).

This particular roadblock emerged at the CNCR Summer Institute, when one person refused to participate in the self- and peer-evaluation exercise; she felt that the questions about interpersonal skills were "too personal" and that the experience of receiving feedback from others on these skills was "too invasive." Other students may express resistance by giving the exercise little time or attention, or providing others with superficial rather than substantive feedback.

In the case of the Summer Institute participant who refused to participate in the exercise, CNCR faculty managed the situation in a manner 
consistent with their philosophy of respecting each individual's dignity and right to make decisions that are best for him or her. The faculty do not attempt to coerce or influence learners into participating in activities in which they feel uncomfortable; nor do they pass judgment on learners for decisions they make regarding participation, recognizing that each person comes to the learning transaction with a unique background and experience of conflict.

As a result of this philosophy, faculty allowed the participant the space to decide not to participate. This decision was supported by the fact that the leaders had communicated verbally and nonverbally throughout the training experience that, out of respect for learners' individual needs, faculty and staff would respect each person's right not to participate in parts of the training.

In response to these roadblocks observed by the CNCR, we offer three suggestions for meeting challenges. First, do not underestimate the importance of the coach's role in holding the process. Raider, Coleman, and Gerson (2000) report that although participants in training often "cognitively grasp the principles of collaboration and want to use them, they still act out competitive or avoidant orientation" (p. 506).

Senge (1995) refers to the role the coach plays in this debriefing session as "holding the dialogue." To support the coaches themselves, the CNCR faculty employs a consistent model for coaching, training coaches, and providing feedback to coaches prior to actually using them in the mediation workshops. Faculty also encourage the participants to provide feedback to their coaches through completing written evaluations, which may be discussed in the daily debriefing meetings. This philosophy is consistent with Schön's theory (1983) that reflection-in-action on the part of the teacher enhances student learning.

The CNCR model of coach training focuses on five steps for coaching role plays: briefing, convening, intervening, closing, and debriefing. Briefing the learners includes establishing rapport and clarifying the goals of the mediation. Convening involves simply reminding the learners of the time constraints and inviting them to begin the role play. Intervening is reserved only for an occasion in which the coach observes that the role play is seriously off-task or the learners are confused or not focused on the learning objectives. Closing is the stage in which the coach calls for the mediation role play to end, asks the learners to step out of role, and allows a "quick release" discussion about the role play itself. Finally, in debriefing, the coach acknowledges the efforts of the learners and asks them to come 
out of their mediation roles; moving away from the roles in the mediation and back into one's role as a reflective learner can be challenging for some learners. Coaches facilitate this process by asking questions to guide the reflection and feedback process.

Second, educators must clarify to participants that the purpose of the coach's critical feedback is to make participants better mediators, not to impart summative evaluation or judgment. Learners must clearly understand this role and trust the coaches in it before the process begins.

Finally, it is essential that training be conducted in a context that emphasizes building positive relationships and does not replicate the hierarchical structure of the university setting. Unequal distribution of power contributes to interpersonal and intergroup conflict; it also affects the mechanisms through which such conflict may be resolved (Shinn and Perkins, 2000). Factors such as ethnicity, race, gender, socioeconomic background, education, and professional affiliation contribute to the extent to which participants have power in their own organization to address conflict. Participants may also differ widely in their needs, self-perceptions, priorities, and past experience with conflict (Seashore, Seashore, and Weinberg, 1997). To the extent that it is possible with human participants, such power differentials should not be replicated in the training; instead, these dynamics must be addressed openly and honestly, so that participants learn strategies to resolve conflict embedded in the context of power relationships.

\section{IR as an Evaluative Measure of Training Objectives}

If interactive reflection is such an important component of conflict resolution, should development of this competency be, at least in part, the measure by which conflict resolution training is measured? Evaluation of the training experience can be understood by looking separately at the components of teaching and learning. The first step is to identify whether or not the instructors and coaches are modeling the conflict resolution techniques they want to see in their students: "The key is to embody the kind of reflective inquiry that you aspire to see in others" (Isaacs, 1999, p. 297).

The next evaluative question, then, is whether or not the participants have met the training objectives established by the facilitators. In other words, is sufficient learning occurring to ensure that at the end of the session participants are competent conflict resolvers? 
Variability in outcome from one participant to the next cannot be understood simply as a function of training experience; a significant challenge to reaching competency in conflict resolution arises from the developmental skills and abilities each learner brings to the table in the first place. Evaluation of the curriculum and training experience, then, should take into consideration the progress of participants over the learning process, rather than only the final level of competency. Measures of adult development, especially reflective judgment (King and Kitchener, 1994), abstract reasoning, epistemological beliefs (Dewey, 1933), and tolerance of ambiguity (King and Kitchener, 1994), may permit some insight regarding the behavior, attitude, and cognition the learner brings to the learning transaction, which can shed more light on the meaning of the training outcomes. Such information may also enable facilitators to improve the curriculum, ensuring that it is supportive of and appropriately challenging to learners at a range of developmental stages (Dewey, 1933).

Lederman and Niess (2000) address a common misperception about how critical reflection is learned: "You may be of the opinion that students will learn about inquiry and about problem solving and reasoning simply by experiencing these activities. Unfortunately, this intuitive assumption is not supported by the empirical literature. Teachers need explicitly to have students reflect on their problem solving behaviors and approaches to scientific inquiry if they are to develop understandings about these critically important skills. Such student understanding does not develop automatically" (p. 115). Of central importance to evaluating conflict resolution training, then, are these questions: To what extent does the program teach the skills required for reflection explicitly? To what extent are students offered a chance to practice and receive feedback on this skill in development?

\section{Limitations and Risks}

Like any learning experience, interactive reflection can have unintended consequences. It is the responsibility of the ethical, learner-centered instructor and facilitator to be aware of these potential outcomes and sensitive to learners' needs throughout the process.

Learners may disclose sensitive or painful personal information and be unable to move past the experience. These disclosures may take the form of personal information or experiences that are revealed in group conversation. Alternatively, the transformative learning experience itself may 
involve an intense sense of loss, since learners are giving up earlier, more comfortable ways of seeing the world and themselves through the learning process (Mezirow, 2000). Although such change may represent growth, this development does not absorb the confusion and pain involved in some learning. Since IR is a teaching strategy and not a therapeutic intervention, there is no mental health provider on hand to help people who have moved into a difficult emotional place recover from such an experience. This outcome would negatively affect the immediate learning of the student and could create negative expectations about future learning opportunities as well.

Some group members may not deliver critical feedback constructively. The sheer volume of scholarly and popular literature on this topic suggests that skillful delivery of critical feedback is not a common skill. If other learners experience receiving feedback as painful, they may respond with aggressive behavior or retreat and withdraw, neither of which facilitates the processes of individual and group learning.

Similarly, if group members deliver feedback in a hurtful manner in front of other members, the recipient of the feedback could lose face in front of them. The result is humiliation on the part of the learner and a sense of distrust among all learners. Students learn from such an event that the learning environment is not a safe one. The consequence is that learners do not take the risks needed to support transformative learning (Mezirow, 2000).

Despite an instructor's best efforts to communicate the role of feedback in learning, some learners may still consider evaluation to be a negative experience of being criticized or attacked. Even if a student has an attitude favorable to learning, negative feedback can be difficult to swallow; a learner with a performance-oriented attitude may fear negative feedback and therefore find the IR process aversive. This outcome could cause the learner not to learn from the IR experience and to avoid similar learning opportunities in the future.

\section{Conclusion}

As a learning strategy, interactive reflection addresses intrapersonal and interpersonal processes, among them attitudes, beliefs, and cognitions related to resolving conflict. Some of the core competencies of conflict resolution, such as effective communication, perspective taking, empathy, critical reflection, awareness of defense mechanisms, and effective exchange of feedback, 
may be developed through learning activities, including self- and groupassessments and role plays that are based on the practice of interactive reflection.

When supporting learners in the process of interactive reflection as well as in assessing their progress, it is important to consider the skills, beliefs, abilities, and experiences that they bring to the learning transaction. Of particular importance for interactive reflection is the teachers' and coaches' understanding of learners' developmental stages and the constraints and opportunities that this level reflects. Such awareness allows instructors to adapt the learning experience to fit the learners, facilitating development of key skills.

Future research may examine the extent to which particular strategies of IR promote these and other outcomes, individual and group characteristics that present roadblocks to learning, and methods through which educators overcome some of these challenges to facilitate better conflict resolution skills in learners.

\section{Appendix}

These are the goals of the Board of Regents' Initiative and Policy Direction on Conflict Resolution:

- To establish a systemwide conflict resolution program that maximizes collaborative resources and guidance for institutional processes and practices, which are developed for and well integrated into the particular institutional culture of each campus

- To decrease reliance on adversarial processes, such as formal grievances and appeals and courtroom litigation, both within the system and in its dealings with other persons and agencies

- To achieve timely, equitable, and satisfactory resolutions at the lowest possible level within the system and at its institutions in the most efficient and cost-effective manner commensurate with the interests and rights of all concerned, and reduce conflict recurrence while anticipating and responding to future conflicts

- To make the institutional environment for students, faculty, and staff more protective of human dignity and trust, more respectful of the value of conflict, and more effective in fostering communication and community

- To make the University System of Georgia an exemplary and nationally recognized leader in the development of alternative dispute resolution for higher education 


\section{References}

Al-Tabtabai, H., Alex, A. P., and Aboualfotouh, A. "Conflict Resolution Using Cognitive Analysis Approach." Project Management Journal, 2001, 32, 4-16.

Argyris, C. "Teaching Smart People How to Learn." Harvard Business Review, May-June 1991, pp. 99-109.

Belenky, M. F., and Stanton, A. V. "Inequality, Development, and Connected Knowing." In J. Mezirow (ed.), Learning as Transformation: Critical Perspectives on a Theory in Progress. San Francisco: Jossey-Bass, 2000.

Bransford, J. D., Brown, A. L., and Cocking, R. R. How People Learn: Brain, Mind, Experience, and School. Washington, D.C.: National Academy Press, 2000.

Dewey, J. How We Think: A Restatement of the Relation of Reflective Thinking to the Educative Process. Boston: Heath, 1933.

Isaacs, W. Dialogue and the Art of Thinking Together. New York: Currency, 1999. Kegan, R. In Over Our Heads: The Mental Demands of Modern Life. Cambridge, Mass.: Harvard University Press, 1994.

King, P. M., and Kitchener, K. S. Developing Reflective Judgment. San Francisco: Jossey-Bass, 1994.

Kolb, D. A. Experiential Learning. Upper Saddle River, N.J.: Prentice Hall, 1984.

Kressel, K. "Mediation." In M. Deutsch and P. T. Coleman (eds.), Handbook of Conflict Resolution: Theory and Practice. San Francisco: Jossey-Bass, 2000.

Kurfiss, J. G. Critical Thinking: Theory, Research, Practice, and Possibilities. ASHEERIC Higher Education Report no. 2. Washington, D.C.: Association for the Study of Higher Education, 1988.

Lederman, N. G., and Niess, M. L. "Problem Solving and Solving Problems: Inquiry About Inquiry." In School Science and Mathematics. Bowling Green, Ky.: School Science and Mathematics Association, 2000.

London, M., Larsen, H. H., and Thisted, L. N. "Relationships Between Feedback and Self-Development." Group and Organizational Management, 1999, $24,5-27$.

Luft, J. Group Processes: An Introduction to Group Dynamics. Palo Alto, Calif.: Mayfield, 1970.

Marsick, V. J., and Sauquet, A. "Learning Through Reflection." In M. Deutsch (ed.), Handbook of Conflict Resolution. San Francisco: Jossey-Bass, 2000.

Mezirow, J. "How Critical Reflection Triggers Transformative Learning." In J. Mezirow (ed.), Fostering Critical Reflection in Adulthood. San Francisco: Jossey-Bass, 2000.

Page, B. J., and Hulse-Killacky, D. "Development and Validation of the Corrective Feedback Self-Efficacy Instrument." Journal for Specialists in Group Work, 1999, 24, 37-54.

Palmer, P. The Courage to Teach: Exploring the Inner Landscape of a Teacher's Life. San Francisco: Jossey-Bass, 1998. 
Raider, E., Coleman, S., and Gerson, J. "Teaching Conflict Resolution Skills in a Workshop." In M. Deutsch (ed.), Handbook of Conflict Resolution. San Francisco: Jossey-Bass, 2000.

Schön, D. The Reflective Practitioner: How Professionals Think in Action. New York: Basic Books, 1983.

Schwartz, R. M. The Skilled Facilitator. San Francisco: Jossey-Bass, 1994.

Seashore, C. N., Seashore, E. W., and Weinberg, G. M. What Did You Say? The Art of Giving and Receiving Feedback. Columbia, Md.: Bingham House Books, 1997.

Senge, P. The Fifth Discipline: The Art and Practice of the Learning Organization. New York: Doubleday, 1995.

Shinn, M., and Perkins, D.N.T. "Contributions from Organizational Psychology." In J. Rappaport and E. Seidman (eds.), Handbook of Community Psychology. New York: Kluwer Academic/Plenum, 2000.

Snyder, M. "Self-Monitoring of Expressive Behavior." Journal of Personality and Social Psychology, 1974, 30, 526-537.

Stone, D., Patton, B., and Heen, S. Difficult Conversations: How to Discuss What Matters Most. New York: Penguin, 1999.

Allison Patten McGuire is a doctoral candidate in community psychology at Peabody College at Vanderbilt University. She researches adolescent development in communities and teaches in the Human and Organizational Development program at Vanderbilt.

Lin Inlow is the director of education and training at the Consortium on Negotiation and Conflict Resolution at Georgia State University and continues to direct the CNCR's Summer Institute on Conflict Management in Higher Education. 